\title{
Computation of Pressure on the Protective Structure to the Instable Slope of Pipeline Trench
}

\author{
Jianyong Li, Guangxiang Yuan, Siwei Wang \& Zhiquan Huang
}

\author{
Department of Underground Space Engineering, School of Resources and Environment, North \\ China University of Water Resources and Electric Power, Zhengzhou, 450045, China.
}

Keywords: pipeline trench, instability of slope, protective structure, computation of pressure.

\begin{abstract}
The stability of trench slope of pipeline engineering, such as water conservancy, municipal, energy and other areas, has an important influence to the safe construction. According to the design requirements of temporary and mobile protective structure in the pipeline project, which guarantee the safety of construction personnel, firstly the various factors affecting the stability of slope of pipeline after excavation is analysed by applying geological method. Then, the interaction mechanism between the slope soil and the protective structure is studied. After that, the computing method of the protective structure is established by using the classical earth pressure theory. These methods were verified and applied in engineering examples. The results show that, this method, which uses different calculation mode of earth pressure for different lithology and different conditions, has a positive significance to the rational design of protective structure in pipeline construction.
\end{abstract}

\section{Introduction}

The slope of trench exists widely in the engineering of petroleum and natural gas, hydraulic channel, municipal water supply and drainage and many other fields. The stability of trench slope has a direct influence on the safe construction of pipeline engineering. If a trench slope becomes instable and slides, it will threaten seriously the personnel working in the trench [1-3]. Therefore, while in the process of pipes welding, some protective structures are adopted to ensure the safety of personnel and equipment.

Generally, the burial depth of pipeline engineering is shallow, and the width of trench limited [47]. The design of temporary protective structure in construction is determined according to the results of static computation [8-10]. The classical theory of earth pressure have applied maturely on the design of permanent retaining structure, but little on the temporary, mobile protective structures to guarantee the safety of personnel of construction in the pipeline engineering. And the studies on the factors of influence and mechanisms of the protective structures are less in the condition of different lithology, different combinations of loads. The interactions between the accumulation of rock and soil after the trench slope instable and the protective structures are analysed from the qualitative and quantitative perspective, and so are the modes of the related computations. The purpose is that the rational advices can be provided to the design of protective structures that guarantee the safe construction of pipeline engineering.

\section{Interaction between the slope of trench and the protective structure}

\section{Analysis of Influence Factors for the Instable Slope of Pipeline Trench.}

The factors of influencing the stability of trench slope, especially including the factors of deformation and failure, should be studied to provide a theoretical basis for the design of protective structures of construction. The stability is influenced by many factors that can be divided into two types: internal factors and external factors. The internal factor includes the classes of rock and soil which are the materials of the trench slope, physical and mechanical properties of rock and soil, geological structures, the structure of rock mass, the role of water and so on. The external factors includes the types and stiffness of retaining structures, the direction and magnitude of displacement of the retaining structures compared to the rock mass, the condition of loads, vibration, 
transformation of the shape of trench slope, earthquake, weather, plants and so on.

The differences of stratum and lithology are the main factors influencing the stability of trench slope. The slopes in some strata developed greatly, and are relevant to particular minerals and weathering residuals which are prone to form the sliding zones, e.g., fissured clay, mud stone and ancient mud metamorphic rocks which are easy slippery strata. Secondly, lithology has a direct influence on the deformation and failure of trench slope. Hard and intact rock of block shape or thick layer may form steep and stable slope. However, in the area of mud or muddy soft soil, it is hard to excavate a slope because of the deformation of plastic flow. A trench slope composed of some strata keeps stable in the dry or natural state, but once submerged in water, the strength of rock is greatly reduced and the slope will be instable. The lithology here includes physical, chemical and mechanical properties of rock, especially the mechanical strength in the condition of saturation is the main factor influencing the stability of trench slope.

Water influences obviously the stability of trench slope. Seepage of underground water has a dynamic water pressure on the slope. Further, water produces a softening effect on the rock mass of trench slope, and water erosion damages directly on the trench slope of pipeline engineering.

Earthquake, large scale blasting and mechanical vibration may cause transient changes of stress, and affect the stability of trench slope. Vibration can also damage the connections between the sandy particles, and liquefaction of saturated sand may occur.

The shape has a direct effect on the stability of pipeline trench slope. The shape refers to the height, length, profile, flat shape and surface conditions etc. For a trench slope of homogeneous rock or soil, the steeper the slope is, the more dangerous, so is the height. When the slope is controlled by the gently inclined discontinuities with the same direction, the stability is irrelevant with angle, and is determined by the height. In addition.

Because of the construction of engineering, the static loads such as pile soil and other materials on the both sides of the trench, the dynamic loads such as mechanical excavation and automobile transportation, are not conducive to the stability of trench slope.

\section{Interaction between the Slope of Trench and the Protective Structure.}

After the excavation of the trench, the original equilibrium state of stress in the rock and soil will be destroyed. The rock mass around the surface will rebound in the process of unloading. A new field of stress will be formed, and will lead to the effects of distribution and concentration of stress.

In fact, constrained by landform, the trench slope in mountain areas are nearly upright. Therefore, after excavation, the concentration of stress is obvious, and the rock and soils tend to slide towards the trench. If the new formed stresses are greater than the strength of rock and soil, damages will occur. If no supports are added to the slope, the trench may be buried and the pipeline will be destroyed by the rock and soil in the condition of large momentum. Worse, if workers are under construction in the trench, casualties may be caused. Since the trench slope can be supported, but most of these slopes are usually temporary and will be buried after the pipelines are welded. This will cause a waste of resources. So after the excavation, the protective structures of construction will be placed into the trench to guarantee the safety of personnel and equipment. When the protective structures are placed, the rock and soil with deformation and failure will produce an extrusion effect on the structure, the pressure will be generated.

The design sections of pipeline trench usually have requirements of sloping. While in the construction, the protective structure can be regarded as rigid body which is perpendicular to the bottom of trench. Therefore, if the slope has pressure on the protective structure, the prerequisite is that the slope is instable at first and then landslide body is in contact with the protective structure. Finally, the equilibrium will be achieved with the constraints increased gradually. At this time, the force of constraints is equal to the pressure on the protective structure. The pressure is an important mechanical basis for the design of these structures.

The slope angle of trench equal to $90^{\circ}$ is common in the rock strata, and also occurs in the nonstandard construction. Starting from the angle of slope, the stability of vertical slope is the worst compared to the inclined slope. Because the deformation or energy dissipation is not enough and the pressure on the protective structure is the largest while the slope has been instable and destroyed. 
In general, the trench is excavated in the range of shallow depth which is not more than $10 \mathrm{~m}$. This determines that the scale of landslide is not large and the velocity of sliding is quite low. The analysis from the view of statics can meet the needs of practical engineering. Of course, if the height of protective structure is lower than the depth of trench, there may be pressure on the roof of the structure, besides the one on the wall.

\section{Pressure computation of the slope of trench to the protective structure}

\section{Computation of lateral pressure of rock and soil}

In the area with thick covers of Quaternary period, because of the loose structure of materials, it is not suitable to excavate the high and steep slope. Therefore, the height of two sides of trench is usually the same in the flat zones. However, in the area of rocks which are hard or soft, the excavation is usually conducted along the foot of mountain. One side of trench is high, and the other is low. The high slope is generally considered, because the higher the slope is, the larger the pressure is. Once the protective structure meets the requirements of high slope, the low side must be satisfied.

According to the interaction between the pile soil of landslide of trench slope and the protective structure, the pressure can be computed by the theory of Rankine or the theory of Coulomb. The model of computation is shown in Fig. 1. When the slope are composed of different layers of rock and soil which have different physical and mechanical properties, the vertical stress ${ }^{\sigma_{z}}$ should be computed at first, and then the coefficient of earth pressure can be obtained in terms of the different values of ${ }^{\varphi}$ related to the stratum. Finally, the strength of earth pressure and the total pressure can be calculated by the formula of the above theories.

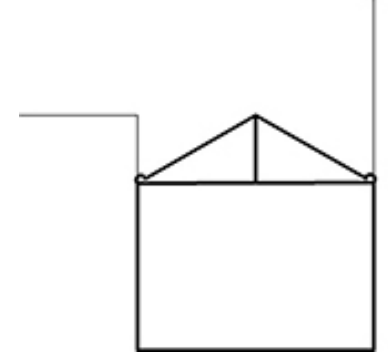

Fig.1: Protective structure

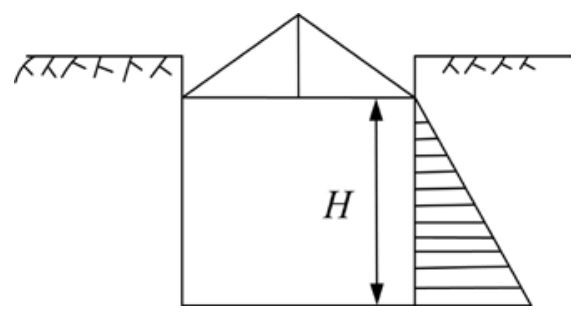

Fig.2: Computing mode of active earth pressure

(1) Earth pressure at rest.

When the trench is excavated or the instable slope is contact with a protective structure, if the structure is rigid and keep still, the pressure on the structure can be viewed as earth pressure at rest.

$e_{0}=\gamma z K_{0}$

$K_{0}$ is the coefficient of earth pressure at rest; $\gamma$ is the bulk density; $z$ is the depth of computing point.

The magnitude of earth pressure at rest changes with the depth. The resultant of total earth pressure at rest per meter is:

$$
E_{0}=\frac{1}{2} \gamma H^{2} K_{0}
$$

(2) Active earth pressure.

Assumed that the protective structure is vertical and smooth, if the structure leaves from the fillings, the active earth pressure will appear. In accordance with the practical cases of engineering, the pressure can be computed by the theory of Rankine or of Coulomb, as shown in Fig. 2.

If there are uniform loads $q$ in the surface of pile soil, the vertical stress of an soil element in depth $z$ is $\sigma_{z}=\gamma z+q$. When the earth pressure caused by uniform loads cannot lead to a zone of tension in the pile soil, the active earth pressure is

$$
e_{a}=\gamma z K_{a}+q K_{a}-2 c \sqrt{K_{a}}
$$

The total active earth pressure:

$$
E_{a}=\frac{1}{2} \gamma H^{2} K_{a}+q H K_{a}-2 c H \sqrt{K_{a}}
$$


$K_{a}$ is the coefficient of active earth pressure of Rankine; $c$ is the cohesion.

(3) Passive earth pressure.

In general, most of the pressure on the protective structure caused by the pile soil of instable slope are earth pressure at rest and active earth pressure. Sometimes, there are the cases of passive earth pressure.

Total passive earth pressure is:

$$
e_{p}=\gamma z K_{p}+q K_{p}+2 c \sqrt{K_{p}}
$$

$$
E_{p}=\frac{1}{2} \gamma H^{2} K_{p}+q H K_{p}+2 c H \sqrt{K_{p}}
$$

$K_{p}$ is coefficient of passive earth pressure of Rankine.

(4) Lateral pressure of rock

For the rock slope of trench, its pressure on the protective structure is not only affected by the physical and mechanical properties of rock, but also controlled by the discontinuities. Therefore, a rock slope should be analysed concretely in the concrete conditions.

A rock slope with fragmental and granular structure can be computed according to the theory of Coulomb, as shown in Fig. 3.

$$
E_{a}=\frac{1}{2} \gamma H^{2} K_{a k}
$$

$K_{a k}$ is coefficient of active earth pressure of Coulomb:

$$
K_{a k}=\frac{\cos ^{2}(\varphi-\alpha)}{\cos ^{2} \alpha \cos (\alpha+\delta)\left[1+\sqrt{\frac{\sin (\varphi+\delta) \sin (\varphi-\beta)}{\cos (\alpha+\delta) \cos (\alpha-\beta)}}\right]^{2}}
$$

\section{Rainfall.}

Do not number your paper: After a rainfall, part of a slope is full of water. The pressure on the back of wall is composed of gravity of soil and hydrostatic pressure. While computing the earth pressure caused by gravity, the bulk density under water should to be float density. The effects of water on the earth pressure is shown in Fig. 4.

Because the trench is usually shallow, the dynamic pressure caused by seepage can be omitted.

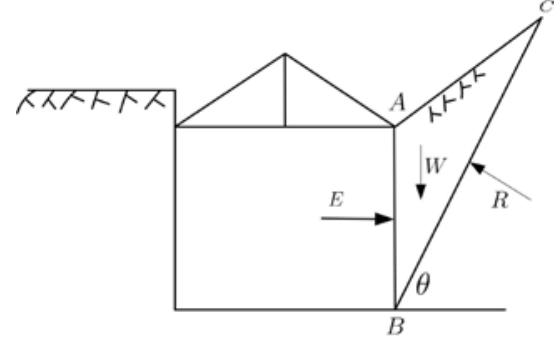

Fig.3: Computing mode of Coulomb

\section{Dynamic Loads.}

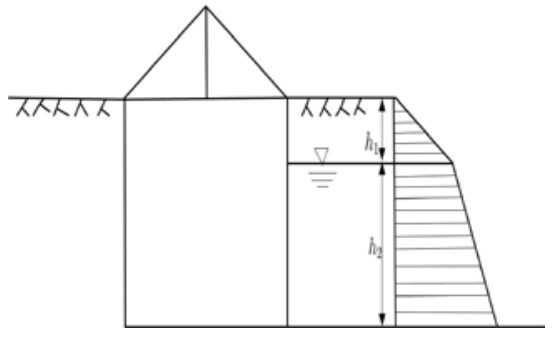

Fig.4: Computing in a rainfall

The case of dynamic load is often processed by pseudo statics method. The inertia force generated by earthquake can be added to the sliding body of rock and soil to be combined into an equivalent weight with the gravity of soil. Finally, Static problem can be computed according to the theory of Coulomb.

\section{Case study}

For a pipeline project of natural gas in western area of China, the mechanical parameters of rock and soil in the trench slope are shown in Table 1 . According to the topography and lithology, the computing section can be divided into three typical strata: sand pebble, loess and general clay. Three cases including natural state, rainfall and dynamic loads can be computed according to the method described in the above, in which acceleration equals to $0.15 \mathrm{~g}$. 
Table 1 Parameters of rock and soil in different lithology and different cases

\begin{tabular}{c|c|ccc}
\hline \multicolumn{2}{c|}{} & $\begin{array}{c}\text { Cohesion } \\
(\mathrm{Pa})\end{array}$ & $\begin{array}{c}\text { Friction Angle } \\
\left({ }^{\circ}\right)\end{array}$ & $\begin{array}{c}\text { Density } \\
\left(\mathrm{kN} / \mathrm{m}^{3}\right)\end{array}$ \\
\hline \multirow{2}{*}{$\begin{array}{c}\text { Sand and } \\
\text { Gravel }\end{array}$} & Natural & 0 & 35 & 20 \\
& Rainfall & 0 & 30 & 22 \\
& Dynamic & 0 & 35 & 20 \\
\hline \multirow{3}{*}{ Loess } & Natural & 1000 & 20 & 15 \\
& Rainfall & 100 & 18 & 18 \\
& Dynamic & 1000 & 20 & 15 \\
\hline \multirow{3}{*}{ Clay } & Natural & 5000 & 25 & 15 \\
& Rainfall & 2000 & 20 & 15 \\
\hline
\end{tabular}

The height of protective structure is $2.5 \mathrm{~m}$. Three types of soil including sand gravel, loess and general clay are computed respectively in the three cases of natural state, rainfall and dynamic load. The results of computing the pressure are shown in Table 2.

Table 2: Pressures on the protective structure in different lithology $(\mathrm{kN})$

\begin{tabular}{ccccccc}
\hline & \multicolumn{2}{c}{ Loess } & \multicolumn{2}{c}{ Sand and Gravel } & \multicolumn{2}{c}{ General Clay } \\
\cline { 2 - 7 } & $2 \mathrm{~m}$ & $10 \mathrm{~m}$ & $2 \mathrm{~m}$ & $10 \mathrm{~m}$ & $2 \mathrm{~m}$ & $10 \mathrm{~m}$ \\
\hline Natural & 41.7 & 265.3 & 48.9 & 352.3 & 16.1 & 262.9 \\
Rainfall & 56.5 & 358.9 & 72.4 & 464.3 & 52.6 & 416.6 \\
Dynamic & 158.4 & -- & 280.6 & -- & 201.6 & -- \\
\hline
\end{tabular}

From the table 2, it can be seen that the pressure of general clay is minimal if the height keep the same, and the pressure of sand and gravel is maximal. For the same type of soil, the active earth pressure in the case of dynamic load is maximal, and is minimal in the natural state. The active earth pressure increases quickly with the height of slope.

\section{Conclusions}

In the process of excavation, the instable slope of trench may lead to a serious threat to safety of personnel and equipment. The impact factors of instable trench slope and interaction mechanisms with protective structures have been analyzed by geological method at first. Then from the view of statics, the pressure on the structures can be computed in the different cases and different conditions of lithology by using the theory of Rankine and Coulomb based on the limit equilibrium thoughts. The practical example show that the pressure obtained with this method is closer to the actual state. This will provide a reliable advice for the design of protective structures which will adopt different forms of structures in the different geological conditions.

For the shallow trench or the case of simple topography, the results computed by the principles of statics generally meet the requirements of the project. However, for the cases of large depth, complex terrain or complicated physical geological phenomena such as collapse, landslide or mudslide in which the velocity of sliding or impact is considered, a special analysis by dynamics need to be studied later.

\section{Acknowledgements}

The study is supported by the Distinguished Research Project of North China University of Water Resources and Electric Power (40274) and the project of the National Natural Science Foundation of China (41402269).

\section{References}

[1] HAO Jianbin, LIU Jianping, et al., A calculation of landslide thrust force to transverse pipelines. Acta Petrolei Sinica, 33(6), pp. 1093-1097, 2012. 
[2] SHEN Yin-bin, ZHU Da-yong, et al., Critical slip field of slopes based on numerical stress field. Rock and Soil Mechanics, 31, pp. 419-423, 2010.

[3] BI Zhong-wei, ZHANG Ming, et al., Dynamic response of slopes under earthquakes. Rock and Soil Mechanics, 30, pp. 180-183, 2009.

[4] WU Chun-qiu, ZHU Yi-wen, CAI Yuan-qi, Dynamic method to assess critical state of slope stability. Rock and Soil Mechanics, 26(5), pp. 784-788, 2005.

[5] HUANG Zhi-quan, WANG An-ming, JIANG Tong, Hazard assessment of landslide and collapse in first-stage project of west line for water-transfer from south to north. Journal of Natural Disasters, 18(4), pp. 78-83, 2009.

[6] HUANG Zhi-quan, WANG Si-jing, The synergetic-bifurcated model for prediction of timing of slope instability and its application. Science in China Ser. E Technological Sciences, 46, pp. 71-79, 2003.

[7] HE Ke-qiang, BAI Jian-ye, WANG Si-jing, Analysis of displacement dynamic features of colluvial landslide induced by rainfall. Rock and Soil Mechanics, 26(5), pp. 705-709, 2005.

[8] SHI Weimin, ZHENG Yingren, The calculation of the lateral pressure on rock construction slope, Geotechnical Engineering Technique, 3, pp. 131-134, 2002.

[9] MING Feng, ZHU Wen-hua, LI Dong-qing, Effect of blasting vibration frequency on slope stability. Journal of Central South University (Science and Technology), 43(11), pp. 44394445, 2012.

[10] YU Boting, SUN Hongyue, SHANG Yuequan, Physical model tests on influence of pipe drainage system on slope residual downslide thrust. Chinese Journal of Rock Mechanics and Engineering, 26(2), pp. 331-337, 2007. 